\title{
ARAŞTIRMA/RESEARCH
}

\section{Tek merkezli borderline over tümörlerinin 5 yıllık retrospektif analizi}

Five years single institution retrospective analysis of the borderline ovarian tumors

Ghanim Khatib ${ }^{1}$, Ümran Küçükgöz Güleç ${ }^{1}$, Ahmet Barış Güzel ${ }^{1}$, Emine Bağır² ${ }^{2}$, Mete Sucu${ }^{1}$, Mehmet Özsürmeli ${ }^{1}$, Mehmet Ali Vardar ${ }^{1}$, Derya Gümürdülü ${ }^{2}$

${ }^{1}$ Çukurova Üniversitesi Tıp Fakültesi, Kadın Hastalıkları ve Doğum Anabilim Dalı, 2Patoloji Anabilim Dalı, Adana, Turkey

\begin{abstract}
Cukurova Medical Journal 2016;41(4):653-657
Abstract

Purpose: The aim of this study was to evaluate the borderline ovarian tumor cases who were operated in our clinic.

Material and Methods: The last 5 years' pathology reports, computer records and archival files of the Çukurova University Medical Faculty Gynecologic Oncology Unit were retrospectively reviewed for the borderline ovarian tumor patients. A total of 41 cases were detected and included in the study. Patients' demographic characteristics, preoperative assessments, operation and pathological features were evaluated.

Results: Patients' mean age was 41 and $85 \%$ of them were premenopausal. Average of the tumor diameter was found to be $10 \mathrm{~cm}$ in the preoperative ultrasound examination. Mean of the preoperative ca125 value was 120 . While total hysterectomy + bilateral salpingo-oophorectomy was applied to 12 cases, unilateral salpingo-oophorectomy was performed in the remaining 29 patients. Lymphadenectomy was carried out in $41.5 \%$ of the patients. Serous borderline was the most common histology $(70.7 \%)$. Majority of the cases was with stage I disease $(90.2 \%)$. No recurrences were determined among the study population.

Conclusion: Borderline ovarian tumors have a favorable prognosis and therefore, unilateral salpingo-oophorectomy

Öz

Amaç: Bu çalışmada, kliniğimizde son 5 yllda opere edilen bordeline over tümörlü vakaların değerlendirilmesi amaçlanmıştır.

Gereç ve Yöntem: Çukurova Üniversitesi Tip Fakültesi Jinekolojik Onkoloji biriminde son 5 yll içerisinde opere edilen borderline over tümörlü olguların, patoloji raporları ve birimin bilgisayar kayıtları ile arşiv dosyaları retrospektif bir șekilde tarandi. Toplam 41 vaka tespit edilip çalışmaya dahil edildi. Olguların demografik karakteristikleri, preoperatif muayene bulguları, operasyon ve patoloji özellikleri değerlendirildi.

Bulgular: Hastaların ortalama yaşı 41 idi ve \%85'i premenopozal dönemde idi. Preoperatif dönemde bakılan ultrasonda, tümörün ortalama çap1 $10 \mathrm{~cm}$ olarak ölçüldü. Operasyon öncesi ortalama ca125 değeri 120 olarak tespit edildi. Total histerektomi + bilateral salpingooferektomi 12 hastaya uygulanırken, geri kalan 29 hastaya unilateral salpingooferektomi uygulandi. Lenfadenektomi, hastaların \%41.5'inde gerçekleştirildi. En sık seröz histopatolojik tip (\%70.7) izlendi. Hastaların çoğunda (\%90.2) tümör, evre I'de idi. Hiç bir olguda nüks tespit edilmedi.

Sonuç: Borderline over tümörleri, iyi prognoza sahip olduğundan, fertilite arzusu olan hastalarda, unilateral salpingoferektomi güvenle önerilebilecek bir tedavi şeklidir.
\end{abstract} can be suggested to be a safely treatment approach for patients who desire to protect their fertility.

Key words: Borderline ovarian tumors, salpingooophorectomy, fertility sparing surgery

\section{GİRİŞ}

Borderline over tümörleri (BOT) stromal invazyon göstermeyen atipik proliferasyona sahip epitelyal
Anahtar kelimeler: Borderline over tümörleri, salpingooferektomi, fertilite koruyucu cerrahi

over tümörlerini ifade etmektedir ${ }^{1}$. BOT tüm overyan epitelyal tümörlerin \%10-15'ini oluşturur. Epitelyal over karsinomlarına k1yasla prognozları mükemmeldir ${ }^{2}$. Genelde erken evrede saptanırlar ve 
5 yıllık sağkalım oranları \%100'e yakındır ${ }^{3}$. Histopatolojik olarak seröz, müsinöz, endometroid, nadiren de clear cell ve brenner tümör şeklinde olabilirler. En s1k seröz borderline over tümörleri bildirilmekle birlikte Çin ve Japonya gibi Asya ülkelerinden gelen yayınlarda müsinöz tümörler ilk sirada yer almaktadir ${ }^{4}$. Tedavi cerrahiden ibarettir. BOT genellikle genç kadınları etkilemekte ve 30-50 yaş aralığında görülmektedir ${ }^{2} . \mathrm{Bu}$ nedenle bazı hastalarda fertilitenin korunması önem arz etmektedir. Bu hastalarda kistektomi veya tek taraflı salpingooferktomi yapılır, uterus ve karşı over korunarak fertilite devam ettirilir. Postmenopozal ve fertilite arzusu olmayan kadinlarda ise, total histerektomi ve bilateral salpingooferektomi $(\mathrm{TH}+\mathrm{BSO})$ uygun yaklaşımdir ${ }^{2,3,5}$. Over tümörlerinin cerrahi evreleme prosedürü tüm hastalara uygulanmalıdır. Lenf nodu örneklemesi ya da diseksiyonu ise, tartışmalı bir konudur ${ }^{2,3,5}$.

BOT, çoğunlukla asemptomatik olup insidental olarak bulunurlar. Semptom verdiklerinde ise hastalar en sık karın ağrisı ile başvururlar. Preoperatif tanı henüz mümkün görünmemektedir. Ca 125 değerleri de hastaların yaklaşık yarısında artmıştır. Donuk kesit ile \%85'e kadar intraoperatif tanı konulabilmektedir ${ }^{6}$. BOT yavaş büyüyen tümörler olup geç rekkürens söz konusu olabilmektedir. Rekürrens, \%11 dolaylarındadır ve rekürrens gelişen hastalarda \%20-30 arasında malign dönüşüm olabilmektedir ${ }^{7}$. Bu çalışmada, kliniğimizde 5 y1llık süre içerisinde opere edilen borderline over tümörlerin değerlendirilmesi amaçlanmıştır.

\section{GEREÇ VE YÖNTEM}

$\mathrm{Bu}$ retrospektif çalışma tersiyer bir kurumda ve bölge hastanesi özelliğinde olan Çukurova Üniversitesi Tip Fakültesi Balcalı Hastanesi'nin Jinekolojik Onkoloji Kliniğinde gerçekleştirilmiştir. Çalışmanın yürütülmesi için Çukurova Üniversitesi Tıp Fakültesi Etik Kurulu'nun onayı alınmıştır. Kliniğimizin kurulumundan bugüne kadar haftalık yapılan Jinekolojik Onkoloji Konseyinde, tüm vakalar tartışılmaktadır. Histopatolojik tanının konfirmasyonundan sonra, hastalara jinekolojik onkolojik dosya açılarak protokol numarası verilmekte ve kendi kliniğimiz bünyesinde klasik arşiv ile bilgisayar ortamında elektronik kayıt sistemimize kaydedilmektedir. Jinekolojik Onkoloji Biriminin arşiv dosya ve kart, bilgisayar dosyaları ve patoloji raporları tarand1, 2010-2015 yıllar1 arasinda opere edilen toplam 1318 jinekolojik onkolojik vakanın 363'ü over kanseri, bunların da 41'i BOT olarak tespit edildi ve çalışmaya dahil edildi. Adneksiyel kitle ön tanısı ile operasyona alınan hastalarin tanisi perop frozen section incelemesi ile konuldu ve materyalin final patoloji incelemesi ile teyit edildi. Sadece final patolojisi borderline over tümörü olan olgular çalışmanın popülasyonunu oluşturdu. Hastaların yaş, menopoz durumu, parite, ca125 değerleri, preoperatif ultrason bulguları (tümör çap1, septa formasyonu, papillar projeksiyonlar ve asit varllğı), oparasyon özellikleri (lateralite, cerrahi prosedür, lenf nodu diseksiyonu, omentektomi, apendektomi, asit varlığ1), patolojik değerlendirmeleri (histopatolojik tip, implant varlığ1, evre) ve takip bilgileri (operasyon sonrasinda ilk 2 yılda 3 ayda bir, sonraki 3 yılda 6 ayda bir ve daha sonrasinda y1llık) kaydedildi.

\section{İstatistiksel analiz}

İstatistiksel analizler SPSS 22.0 Versiyonu ile gerçekleştirildi. Kategorik ölçümler sayı ve yüzde olarak, sürekli ölçümler ise ortalama ve standart sapma (gerekli yerlerde alt sınır - üst sinır) olarak özetlendi.

\section{BULGULAR}

Çukurova Üniversitesi Tip Fakültesi Jinekolojik Onkoloji Biriminde yapılan bu retrospektif çalışma, 2010-2015 yilları arasinda opere edilen toplam 41 borderline over tümörü vakası ile yürütüldü. Hastaların yaş aralığı 17-88 arasında iken, yaş ortalaması 41.5 \pm 15 yıldı. Büyük çoğunluğu (35, \%85.4) premenopozal dönemde idi. Hastaların özellikleri ve karakteristikleri Tablo 1 ve 2'de özetlenmiştir.

Tablo 1. Hastaların özellikleri

\begin{tabular}{|l|l|l|}
\hline Parametre & ortalama \pm SD & Aralık \\
\hline Yaş & $41.5 \pm 15$ & $17-88$ \\
\hline $\begin{array}{l}\text { Tümör çap1 } \\
(\mathrm{cm})\end{array}$ & $10 \pm 4.5$ & $2,5-23$ \\
\hline Ca125 & $120 \pm 25$ & $9-1371$ \\
\hline
\end{tabular}

Birimin doktorları tarafindan yapılan preoperatif transvajinal veya transabdominal ultrasonografik incelemede; tespit edilen en küçük tümör çap1 $2,5 \mathrm{~cm}$, en büyüğü $23 \mathrm{~cm}$ ve ortalama çap $10 \mathrm{~cm}$ idi. Vakaların 14'ünde (\%34.1) septa formasyonu izlendi. Papillar projeksiyonlar $26 \quad(\% 63.4)$ hastada 
kaydedildi. Ultrasonda asit ise, $18(\% 43.9)$ vakada görüldü. Preoperatif dönemde bakılan ca125 değerleri 9-1371 arasında, ortalama 120 25 olarak ölçüldü.

Cerrahi prosedür olarak 12 hastaya total histerektomi + bilateral salpingooferektomi (TH+BSO) uygulanırken, geri kalan 29 hastaya unilateral salpingooferektomi (USO) uygulandi. Omentektomi $16(\% 39)$ vakada yapıldı. Bilateral pelvik paraaortik lenf nodu diseksiyonu (BPPLND) 17 (\%41.5) hastada gerçekleştirildi. Tümör 19 (\%46.3) vakada sağ overde bulunurken, 14 (\%34.1) vakada solda bulunuyordu ve geriye kalan 8 (\%19.5) vakada ise, bilateral yerleşimli idi. Seröz tip borderline over tümörü, $29(\% 70.7)$ vaka ile hastaların 2/3'ünden fazlasını oluşturdu. Diğer vakaların 11’i (\%26.8) müsinöz ve sadece 1 tanesi
(\%2.4) seromüsinöz histopatolojisine sahipti. Otuz iki (\%78) hasta evre IA, $5(\% 12.2)$ hasta evre IC, 1 (\%2.4) hasta evre II ve $3(\% 7.3)$ hasta evre III hastalığa sahipti. Sadece $2(\% 4.9)$ vakada pozitif lenf nodu saptandi.

Hiçbir hastamızda invazif implant tespit edilmedi. Hastaların takipleri jinekolojik onkoloji biriminde ilk 2 yılda 3 ayda bir, sonraki 3 yılda 6 ayda bir ve daha sonrasinda yıllik jinekolojik muayene, ca125 değerleri ve gerektiğinde radyolojik görüntüleme yöntemleri ile yapılmakta olup, çalışmanın süresi içerisinde hem TH+BSO hem de USO vakalarında nüks saptanmamıştır. Her iki grubun hastalarında da ölüm olmamıştır. $\mathrm{Bu}$ sonuç, yapılan cerrahi prosedüre ve lenfadenektominin yapilip yapılmadığına bakılmaksızın, bordeline over tümörlerinin iyi prgnozuna işaret etmektedir.

Tablo 2. Hastaların karakteristikleri

\begin{tabular}{|c|c|c|c|}
\hline \multicolumn{2}{|l|}{ Parametre } & $\mathrm{N}$ & $(\%)$ \\
\hline \multirow[t]{2}{*}{ Menopoz durumu } & Premenopoz & 35 & $(85.4)$ \\
\hline & Postmenopoz & 6 & $(14.6)$ \\
\hline \multirow[t]{2}{*}{ Septa formasyonu } & Yok & 27 & $(65.9)$ \\
\hline & Var & 14 & (34.1) \\
\hline \multirow[t]{2}{*}{ Papillar projeksiyon } & Yok & 15 & $(36.6)$ \\
\hline & Var & 26 & $(63.4)$ \\
\hline \multirow[t]{2}{*}{ Asit varllğ1 } & Yok & 23 & $(56.1)$ \\
\hline & Var & 18 & $(43.9)$ \\
\hline \multirow[t]{2}{*}{ Cerrahi prosedür } & TH-BSO* & 12 & $(29.3)$ \\
\hline & USO† & 29 & $(70.7)$ \\
\hline \multirow[t]{2}{*}{ Omentektomi } & Yok & 25 & $(61.0)$ \\
\hline & Var & 16 & $(39.0)$ \\
\hline \multirow[t]{2}{*}{ Lenfadenektomi } & Yok & 24 & $(58.5)$ \\
\hline & Var & 17 & $(41.5)$ \\
\hline \multirow[t]{3}{*}{ Tümörün lokalizasyonu } & Sağ & 19 & $(\% 46.3)$ \\
\hline & Sol & 14 & $(\% 34.1)$ \\
\hline & Bilateral & 8 & $(\% 19.5)$ \\
\hline \multirow[t]{3}{*}{ Histopatolojik tip } & Seröz & 29 & $(70.7)$ \\
\hline & Müsinöz & 11 & $(26.8)$ \\
\hline & Seromüsinöz & 1 & $(2.4)$ \\
\hline \multirow[t]{6}{*}{ Evre } & IA & 32 & $(\% 78)$ \\
\hline & IB & 0 & $(0)$ \\
\hline & IC & 5 & $(\% 12.2)$ \\
\hline & II & 1 & $(\% 2.4)$ \\
\hline & III & 3 & $(\% 7.3)$ \\
\hline & IV & 0 & $(0)$ \\
\hline
\end{tabular}

*TH-BSO: total histerektomi-bilateral salpingooferektomi, $\nmid$ USO: unilateral salpingooferektomi

\section{TARTIŞMA}

Borderline over tümörleri veya eski ismiyle düşük malignite potansiyelli over tümörleri stromal invazyon oluşturmayan atipk epitel proliferasyonu ile karakterize tümörleri ifade etmektedir. Bu tümörler her yaşta görülebilir, ancak sıklıkla reprodüktif dönemdeki genç kadınları etkiler. Ortalama görülme yaşı 40'tır ve bunların \%45’i 40 yaşın altındadır ${ }^{6,7}$. Bizim serimizde de hastaların ortalama yaşı 41 idi ve hastaların çoğu premenopozal dönemde idi. BOT'un 
daha çok genç hastalarda görülmesi ve iyi prognozlu olmas1, kistektomi veya USO gibi fertilite koruyucu cerrahileri zorunlu kılmıştır. Fertilitesini tamamlamış hastalarda ise, TH-BSO standart cerrahi şeklidir. Bu tümörlerde komplet evreleme ve lenfadenektomi hep tartışma konusu olmuştur. Jinekolojik onkoloji derneğince yapılan ve 274 üyenin katıldığ1 anket çalışmasında, katılımcıların yüzde 97'si cerrahi evrelemeyi, \%96's1 peritoneal y1kamay1, \%92'si random peritoneal biyopsileri, \%97'si omentektomi veya örneklemesini, \%88'i lenfadenektomiyi (\%89 para-aortik, \%97 pelvik) gerekli gördüğünü belirtmiştir ${ }^{8}$. Türk Jinekolojik Onkoloji Grubu, 539 BOT hastası üzerinde yaptıkları çok merkezli retrospektif çalışmada, kapsamlı cerrahi evreleme, lenf nodu diseksiyonu veya örneklemesi ve apendektomi işlemlerinin faydalı olmadığını öne sürmüştür ${ }^{2}$.

Bendifallah ve arkadaşlarının 186 BOT hastası üzerinde yaptıkları çok merkezli retrospektif çalışmada ise, tanı anındaki hastanın yaşı, evre, histolojik subtip, komplet cerrahi ve cerrahi tipi (radikal veya fertilite koruyucu), artmıss nüks riski ile ilişkili bulunmuştur ve BOT vakalarında nüksü belirlemek için bu 5 faktörden oluşan bir normogram önermişlerdir ${ }^{1}$. İleri evre 49 BOT vakası ile yaptıkları çalışmada, Lesieur ve Arkadaşları, bu hastalarda lenf nodu tutulumunun prognostik faktör olmadığını beyan etmişlerdir ${ }^{3}$. Türkiyeden yapılan 122 vakalık bir çalışmada, yazarlar lenfadenektomi dahil cerrahi evrelemenin nüks hakkında fikir verebileceği ancak toplam sağkalıma dair fikir vermeyebileceği sonucuna varmışlardır ${ }^{9}$. Bizim çalışmamızda, hastaların \%70.7'sine radikal cerrahi (TH-BSO) ve \%29.3'üne fertilite koruyucu cerrahi olarak USO uygulandi. Komplet evreleme cerrahisi ise, $9(\% 22)$ vakada gerçekleştirildi.

BOT hastalarında ca125, üstünde en çok durulan ve en çok çalışılan tümör markerıdır. Gotlieb ve arkadaşları tarafindan yapılan çalışmada, ca125 yüksekliği sırasıyla seröz ve müsinöz BOT’ta $\% 75$ ve $\% 30$ oranında tespit edilmiştir. Aynı çalışmada, müsinöz BOT’ta vakaların yarısında tümör multiloküle ve $\% 40$ oranında papillar yapı içerirken; seröz BOT’ta tümör, vakaların \%30'unda multiloküle ve $\% 78$ 'inde papillar veya solid patern bulunduruyordu ${ }^{10}$. Sunduğumuz bu çalışmada, preoperatif bakilan ca125 değerleri $14(\% 34)$ hastada yüksek bulundu (cutt off değeri 35 alındığında). Ultrason bulgularından papillar projeksiyonlar da hastaların \%63.4’ünde izlendi.
Song ve arkadaşları BOT'un histopatolojik alt tiplerinin dünyadaki sıklık dağılımını araştırmış ve bu amaçla dünyanın her yerinden BOT üzerinde yapılan 51 çalışmayı incelemişlerdir. Genel olarak seröz tip borderline over tümörü Kuzey Amerika, Avrupa ve Orta Doğuda hakimken, Doğu Asyada müsinöz tip ilk sırada görülmektedir. ${ }^{4}$ Bu dağılıma uygun olarak da bizim çalışmamızda en sık seröz tip (\%70.7) arkasından \%26.8 oranıla müsinöz tip izlendi. Terek ve arkadaşlarının çalışmasında, olguların \%91'i evre I, \%6 evre II ve $\% 3$ 'ü evre III olarak bulunmuştur ${ }^{11}$. Benzer şekilde bizim seride, vakaların \%90.2'si evre I, \%2.4'ü evre II ve \%7.3’ü evre III olarak değerlendirildi. Çalışmanın retrospektif oluşu ve vaka sayısının az olması en önemli kıstaslardır. Avantajları ise, tek merkezli olması nedeniyle aynı ekip tarafindan preoperatif değerlendirme, operasyon, patolojik inceleme, tedavi ve takiplerinin yapılması sonucunda standardizasyonun sağlanmış olmasıdır.

Sonuç olarak, borderline over tümörlerinin; mükemmel prognoza sahip olması, çoğunlukla erken evrede saptanması ve genellikle genç kadınları etkilemesi nedeniyle, bu tümörlere fertilite koruyucuu cerrahiler rahatlıkla uygulanabilmektedir.

\section{KAYNAKLAR}

1. Bendifallah S, Ballester M, Uzan C, Fauvet R, Morice $P$, Darai E. Nomogram to predict recurrence in patients with early- and advanced-stage mucinous and serous borderline ovarian tumors. Am J Obstet Gynecol. 2014;211:637 e1-6.

2. Guvenal T, Dursun P, Hasdemir PS, Hanhan M, Güven S, Yetimalar H et al. Effect of surgical staging on 539 patients with borderline ovarian tumors: a Turkish Gynecologic Oncology Group study. Gynecol Oncol. 2013;131:546-50.

3. Lesieur B, Kane A, Duvillard P, Gouy S, Pautier P, Lhommé $\mathrm{C}$ et al. Prognostic value of lymph node involvement in ovarian serous borderline tumors. Am J Obstet Gynecol. 2011;204:438 e1-7.

4. Song T, Lee YY, Choi CH, Kim TJ, Lee JW, Bae DS, et al. Histologic distribution of borderline ovarian tumors worldwide: a systematic review. J Gynecol Oncol. 2013;24:44-51.

5. Romeo M, Pons F, Barretina P, Radua J. Incomplete staging surgery as a major predictor of relapse of borderline ovarian tumor. World J Surg Oncol. 2013;11:13.

6. Sanc1 M, Güngördük K, Gülseren V, Özdemir İA, Ayhan A. Borderline over tümörleri: tanı, tedavi, takip. Türk Jinekolojik Onkoloji Dergisi. 2014;4:11322. 
7. Selçuk İ, Özgü E, Meydanlı MM, Güngör T. Borderline over tümörlerinde cerrahi ve adjuvan kemoterapi. Jinekoloji-Obstetrik ve Neonatoloji Tip Dergisi. 2014;11:101-4.

8. Menzin AW, Gal D, Lovecchio JL. Contemporary surgical management of borderline ovarian tumors: a survey of the Society of Gynecologic Oncologists. Gynecol Oncol. 2000;78:7-9.

9. Ureyen I, Karalok A, Tasci T, Turkmen O, Boran N, Tulunay $\mathrm{G}$ et al. The factors predicting recurrence in patients with serous borderline ovarian tumor. Int $\mathrm{J}$
Gynecol Cancer. 2016;26:66-72.

10. Gotlieb WH, Soriano D, Achiron R, Zalel Y, Davidson B, Kopolovic J et al. CA 125 measurement and ultrasonography in borderline tumors of the ovary. Am J Obstet Gynecol. 2000;183:541-6.

11. Terek MC, Dikmen Y, Özsaran AA, Özsaran AA, Hurşitoğlu S, Elmalı Z et al. Borderline over tümörlerinin değerlendirilmesi: tek merkez 5 ylllk retrospektif analizi. J Turk Soc Obstet Gynecol. 2013;10:103-9. 